\title{
THE NEED FOR SOCIETY PROGRAMS
}

\author{
By B. F. Avery
}

T is well from time to time to think back to the beginning of an institution in order to feel anew the conditions under which it came into existence, to sense the function that it was intended to perform, and to determine in what degree it has fulfilled the expectations of the founders.

The Canadian Society of Forest Engineers has not existed from the beginning. It was created in the minds of a group of men, members of a new profession in Canada, to satisfy a definite need. What that need was is expressed or implied in the "Objects" clearly set down in the constitution of the Society which they founded. The stated objects were three in number:

(1) To advance the members in the theory and practice of Forestry by the discussion of technical and professional topics.

(2) To promote a better mutual acquaintance among Canadian Foresters and to cultivate an esprit de corps among the members of the profession.

(3) To take such steps as may from time to time appear advisable for the purpose of promoting in Canada the interests of the forestry profession as a whole.

It is obvious that the group of foresters who established the Society intended it to be a means toward a broader knowledge of forestry, toward a closer fellowship and greater unity of high purpose among members of the profession in Canada, and toward the continuous promotion in Canada of the interests of the profession. Knowledge, fellowship and high purpose, and the promotion of forestry were the avowed purposes. It may be assumed that those purposes were outlined to meet the immediate or contemplated need. Growth was anticipated and growth would require that steps be taken to meet new conditions.

The means that were undertaken to fulfill the objects of the Society were two: the annual meeting of the members and the publication of a Society magazine. A third, the opportunity to form Sections of the Society, was offered to the members in recent years.

The annual meeting has done much to advance the members in the theory and practice of Forestry through the discussion of technical and professional topics. It has promoted better mutual acquaintance. It has cultivated a unity of high purpose. However the growth that was contemplated at the founding of the Society has taken place, and while at one time it may have been possible for all members to attend the annual meeting, because the numbers were few and the dispersal limited, it is now not possible 
to obtain complete attendance at such a meeting, due to the greatly increased numbers and the widely scattered residence of the members.

The Society Magazine "The Forestry Chronicle" has done much to advance the members in the theory and practice of forestry through the publication of articles dealing with technical and professional topics.

As a medium of expression it has been used to promote greater knowledge, on the part of the Society, of the members who have contributed articles and carried on disecussions through its pages. Too few of the members have availed themselves of the opportunity for expression offered by the "Chron. icle."

However much the annual meeting of the Society and the Forestry Chronicle have done to promote the purpose of the Society, it is evident that the third object has been greatly neglected. The fault does not lie with the founders of the Society or in the constitution which they wrote. The fault lies with the present membership. Each day furnishes an opportunity to make the Society as alive and purposeful as on the day of its creation. The founders knew that the discussion of technical and professional topics, the promotion of better acquaintanceship among the members and the cultivation of esprit de corps were good things at that time, but they also contemplated that from time to time further steps must be taken to promote the interests of forestry in Canada. We have not taken those steps. We have rested upon the efforts and energy of those who founded the Society, accepted the benefits of membership, and expected the Society through some strange, unseen power to promote the interests of the profession without effort on the part of the membership. That the Society cannot do. There must be effort on the part of the membership, and there must be direction of membership effort if there is to be progress.

Is it not true that without giving there can be no receiving? Is it not true that without work there is no reward? Is it not true that unselfish service alone begets loyalty? All general observations in nature and therefore dangerous of application in specific case, but worthy of serious cronsideration nevertheless.

Has the Society the loyalty of its membership? Is the profession reaping a reward through the work of the Society? Are the members of the Society receiving the expected benefits from membership in it?

In a University, in Government Service, in business, progress is planned. The ultimate object is predetermined and a programme of effort is prepared to direct the application of energy toward the desired accomplishment.

The founders of the Society determined that one of the objects of the Society was the promotion of Forestry in Canada. They also recorded that the term "forestry" should be understood to include all the activities in- 
volved in the management of a forest, the object of which is to maintain the production of wood or the beneficial influence of the forest.

It would appear that the step to be taken toward the attainment of the predetermined objective is a plan of action, a programme of work to direct the latent energies of the membership.

What the plan shall be might well form the basis for discussion through the pages of the "Chronicle" until such time as the Society is ready to decide upon the Programme at an annual meeting. It is conceivable that definite action might be taken at the next annual meeting, if the membership will give attention to the idea in the meantime and indicate that it is ready to have the next meeting dedicated to that purpose.

A definite proposition is more apt to stimulate thought and beget action than an abstract idea. It does not require a great amount of searching to discover a concrete project to be undertaken. What is Canada's forest practice? What has been and what is the result of that practice? What changes in that practice are essential to maintain the production of wood or the beneficial influence of the forest? Can the Society answer those questions? To what source should the Canadian press and the Canadian public turn for the answer to those questions if not to the Canadian Society of Forest Engineers? Have we the information to furnish to the Canadian public and to the Canadian press? We have not.

Here, then, is a project; to determine forest practice in Canada; to determine the forest condition resulting from that practice; to determine the adjustments required, if any, in that practice in order that the production of wood or the beneficial influence of the forest may be maintained.

It is a large project, for Canada is a large country. Is it too big for the Society? The challenge has been posted many times in the press through the printing of information dealing with Canada's forest conditions and requirements, that the Society could neither confirm nor deny.

The project is not too big for the Society. It can be carried out through the work of Sections, the formation of which has been contemplated by the constitution. It can be developed by the Sections more effectively if an outline of the project is drawn up by the Society as a whole through the Executive or through a group appointed for the purpose. If, under the plan of procedure, the whole of Canada were divided into large districts, and those districts further divided into smaller unit forest areas, the problem would become less complicated, but it would still be complex. The scope of the project is such as to attract the interest and require the assistance of every member throughout the Dominion. It would furnish definite work for Sections to perform and stimulate through the Sections the advancement of the expressed objects of the Society. 
The Constitution reads "To take such steps as may from time to time appear advisable, for the purpose of promoting in Canada the interest of the forestry profession as a whole."

What shall we do about it?

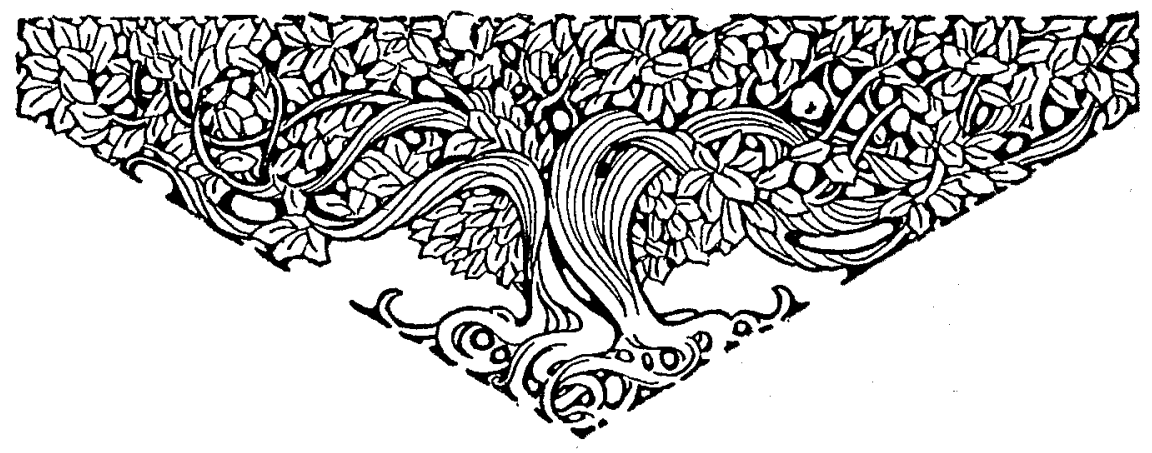

